In the Holmes stereoscope, the constant is 2.24, so that the neutral distance for any stereogram is 2.24 times its own breadth from the lenses.

4. The longitudinal strip of the Holmes instrument can be graduated in this manner to save calculation, so that a stereogram of any breadth can be at once placed on its neutral seat if required, beyond which Con. > Acc. and within which Con. < Acc.

5. For the training of an esotrope, the widest stereogram should be selected that can be certainly fused at the far end of the instrument, and it should be gradually caused to approach. For an exotrope, the narrowest stereogram should be employed, that can be fused as near to the eyes as accommodation permits, and it should be gradually caused to recede.

\title{
A TREATMENT FOR TRAUMATIC SYMBLEPHARON
}

\section{BY}

E. Nicholas Hughes, M.R.C.S., D.O.M.S. HON. OPHTHALMIC SURGEON, WALLASEY COTTAGE HOSPITAL OCULIST TO THE CHESHIRE EDUCATION COMMITTEE

IT too frequently happens, after injuries to the lower lids that a symblepharon forms, and this in spite of all treatment.

The injuries are those which chiefly affect industrial workers, such as lime and acid burns, and burns with molten metal. In these cases the conjunctival surface of the lower lid is, in places, often destroyed, and also areas on the bulbar conjunctiva.

I have had to deal with about twelve such cases during the past two years. The primary object of treatment has been to prevent union between the palpebral and bulbar conjunctival surfaces. The free application of ointments, small rolls of lint soaked in vaseline and placed in the conjunctival fornix, and the very frequent drawing apart of the opposed surfaces have been employed, but in spite of these measures, union between the lid and globe has occurred.

In order to overcome this union between lid and globe, I employed the following simple apparatus and have used it with remarkably good results :

A sufficient length of silver wire (53 Stubb's system in thickness) is bent as shown in diagram, the free ends of the wire being soldered to make a continuous framework. It will be seen that the completed framework consists of two horizontal bars connected at each end by a loop. One of these bars fits into the conjunctival fornix, whilst the other lies outside the lid, the two loops crossing over the lid edge.

Minor adjustments will be found necessary in individual cases 


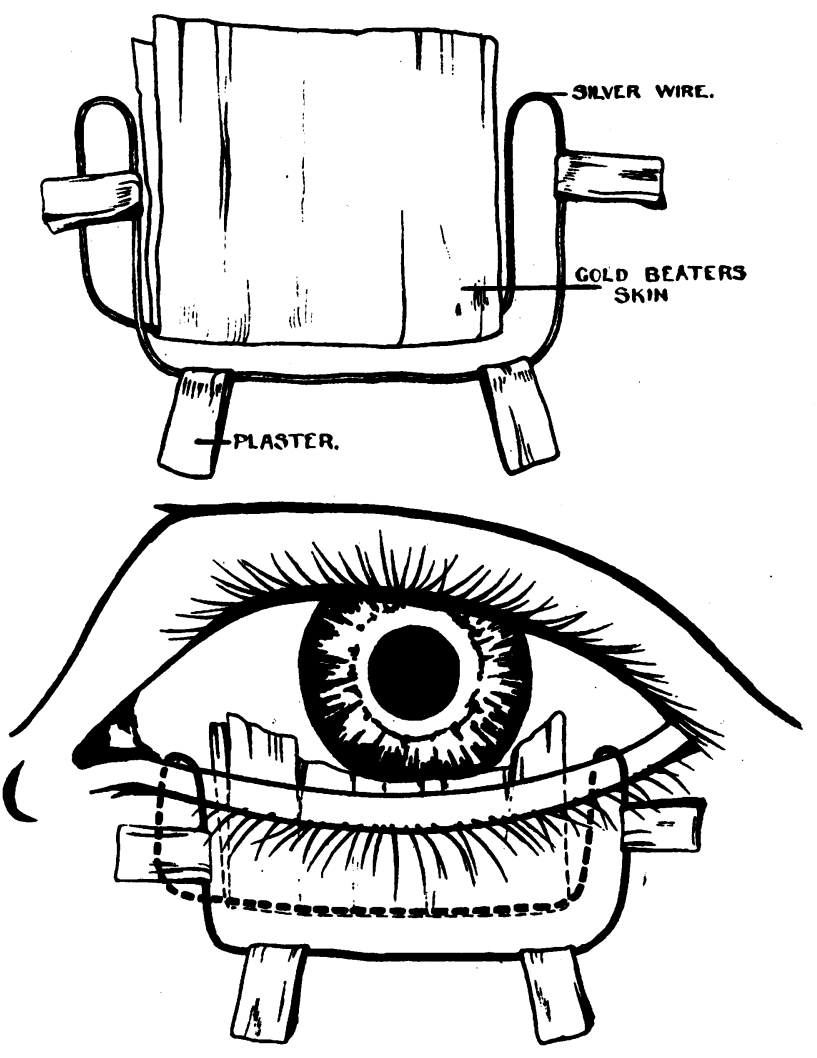

in order to make the framework romfortable, e.g., a slight curvature with the concavity towards the globe will be necessary for comfortable fitting. The ends of the loops should be a few millimetres from each canthus. A small strip of goldbeaters' skin is placed across the horizontal bar of the framework which lies in the fornix, its free border being trimmed with scissors to keep it clear of the cornea.

The diagram shows the goldbeaters' skin and framework in situ. The goldbeaters' skin is sterilized by immersion in 10 per cent. carbolic, then rinsed in sterilized water prior to use. The frame is held in position by strips of adhesive plaster attached to the bar lying outside the lid. The apparatus is removed twice daily for cleansing purposes, a fresh piece of goldbeaters' skin being used on each occasion.

Lotion and antiseptic drops together with a bland oil, e.g., liquid paraffin are instilled at each dressing. Providing the framework fits well the patient can wear the apparatus without discomfort and it should be worn until the bulbar and conjunctival surfaces are hedled. 